\title{
Quarter Car Active Suspension System Design Using Optimal and Robust Control Method
}

\author{
Mustefa Jibril $^{1} \quad$ Dr.Prashanth Alluvada ${ }^{2}$ \\ 1.Department of Electrical \& Computer Engineering, Dire Dawa Institute of Technology, Dire Dawa, Ethiopia \\ 2.Faculty of Electrical \& Computer Engineering, Jimma Institute of Technology, Jimma, Ethiopia
}

\begin{abstract}
This paper offers with the theoretical and computational evaluation of optimal \& robust control problems, with the goal of providing answers to them with MATLAB simulation. For the robust control, $\mu$-synthesis controller and for the optimal control, LQR controller are designed for a quarter car active suspension system to maximize the ride comfort and road handling criteria's of the vehicle. The proposed controllers are designed using Matlab script program using time domain analysis for the four road disturbances (bump, random sine pavement and white noise) for the control targets suspension deflection, body acceleration and body travel. Finally the simulation result prove the effectiveness of the active suspension system with $\mu$-synthesis controller.
\end{abstract}

Keywords:Quarter car active suspension system, optimal control, robust control, linear quadratic regulator DOI: $10.7176 /$ IEL/10-2-04

Publication date:March $31^{\text {st }} 2020$

\section{I.Introduction}

Active suspension system are designed to satisfy specific necessities. In suspension systems, normally two maximum vital capabilities are anticipated to be advanced - disturbance shocking up (i.e. Passenger consolation) and attenuation of the disturbance transfer to the road (i.e. Vehicle dealing with). The first requirement might be supplied as an attenuation of the damped mass acceleration or as a peak minimization of the damped mass vertical displacement. The second one is characterized as an attenuation of the pressure acting on the road or in simple vehicle model as an attenuation of the unsprung mass acceleration. It is apparent that there's a contradiction among those requirements. Effort devoted to passive suspension design is ineffective, due to the fact there is a contradiction among both requirements. The nice end result (in experience of necessities development) can be done by active suspension, this means that that a few additional force can act on system.

The concept of optimal control has been nicely advanced for over forty years. With the advances of computer technique, optimal control is now widely used in multi-disciplinary applications which includes biological structures, conversation networks and socio-monetary systems and so forth. As an end result, increasingly people will benefit greatly via gaining knowledge of to resolve the optimal control problems numerically. Realizing such growing desires, books on optimum control put extra weight on numerical strategies. Necessary situations for diverse systems had been derived and specific solutions were given whilst possible. LQR is a control system that gives the pleasant viable performance with admire to some given degree of performance. The LQR design problem is to design a state feedback controller $\mathrm{K}$ such that the objective function $\mathrm{J}$ is minimized. In this approach a remarks advantage matrix is designed which minimizes the goal characteristic as a way to obtain some compromise among the use of control effort, the significance, and the speed of reaction so that it will assure a stable system.

\section{Mathematical ModEL}

\section{A. Quarter Vehicle Active Suspension System Mathematical Model}

Let's begin with the most effective active suspension system model as shown in Figure 1. It carries two springs (one in suspension and second representing vehicle tires), one dumper and source of energy as actuator. The model is described by way of the differential motion equations:

$$
\begin{aligned}
& m_{b} \ddot{y}_{b}=F-k_{1}\left(y_{b}-y_{w}\right)-D\left(\dot{y}_{b}-\dot{y}_{w}\right) \\
& m_{w} \ddot{y}_{w}=-F+k_{1}\left(y_{b}-y_{w}\right)-k_{2}\left(y_{w}-y_{r}\right)+D\left(\dot{y}_{b}-\dot{y}_{w}\right)
\end{aligned}
$$




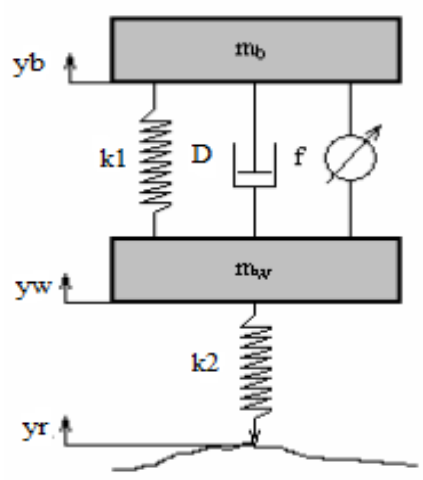

Figure 1: Quarter car active suspension model

Table 1: Parameters of Quarter vehicle Model

\begin{tabular}{|c|c|c|}
\hline Model parameters & symbol & symbol Values \\
\hline Vehicle body mass & $m_{\mathrm{b}}$ & $300 \mathrm{Kg}$ \\
\hline Wheel assembly mass & $m_{\mathrm{w}}$ & $40 \mathrm{Kg}$ \\
\hline Suspension stiffness & $k_{1}$ & $15,000 \mathrm{~N} / \mathrm{m}$ \\
\hline Suspension damping & $k_{2}$ & $150,000 \mathrm{~N} / \mathrm{m}$ \\
\hline Tyre stiffness & $D$ & $1000 \mathrm{~N}-\mathrm{s} / \mathrm{m}$ \\
\hline
\end{tabular}

\section{Road DisturbanCE INPUT SIGNALS}

\section{A. Bump Road Disturbance}

Bump input signal is a simple input to research the suspension system. It simulated a completely intense pressure for a very quick time, such as a car drive through a speed hump. This road disturbance has a maximum height of $5 \mathrm{~cm}$ as shown in Figure 2.

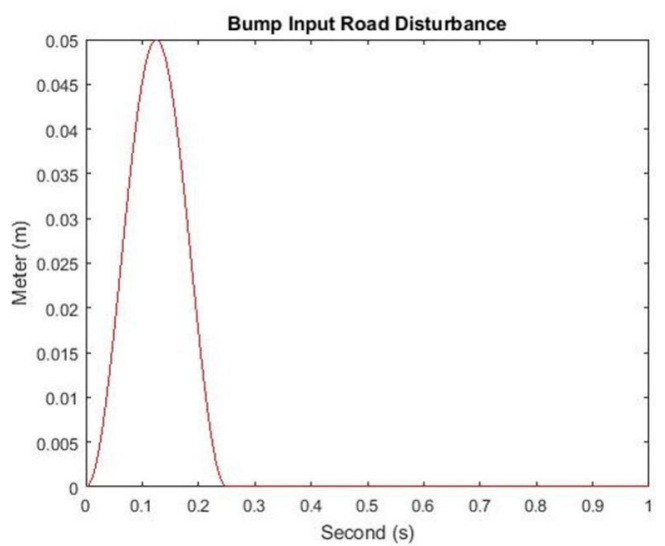

Figure 2: Bump road disturbance

\section{B. Random Road Disturbance}

Numerous researches show that it's far vital to test a vehicle to a random road disturbance to test the spring and damper reply speedy and efficiently. The random road disturbance has a maximum height of $15 \mathrm{~cm}$ and minimum height of $-15 \mathrm{~cm}$ as shown in Figure 3. 


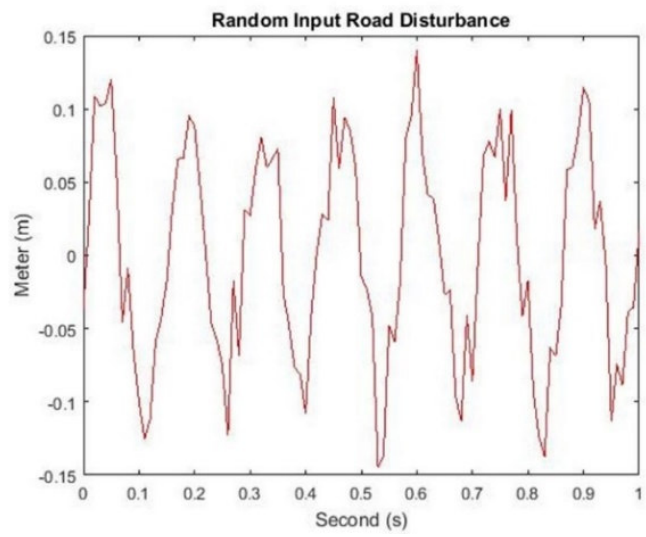

Figure 3: Random road disturbance

\section{Sine Pavement Road Disturbance}

Sine wave input signal can be used to simulate periodic pavement fluctuations. It can take a look at the vehicle suspension system elastic resilience capacity whilst the vehicle reviews a periodic wave pavement. Sine input pavement test is made by means of each car industries before a new automobile drives on road. The sine pavement road disturbance has a height of $-10 \mathrm{~cm}$ to $10 \mathrm{~cm}$ as shown in Figure 4.

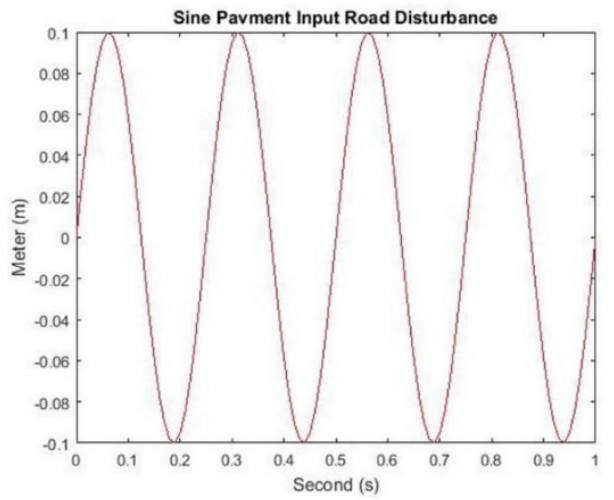

Figure 4: Sine pavement road disturbance

\section{White Noise Road Disturbance}

Numerous researches display that once the automobile speed is consistent, the road roughness is a stochastic system that's subjected to Gauss distribution, and it can't be described accurately by means of mathematical model. The automobile velocity electricity spectral density is a constant, which correspond with the definition and statistical function of the white noise, so it is able to be virtually transformed to the road roughness time domain model as shown in Figure 5.

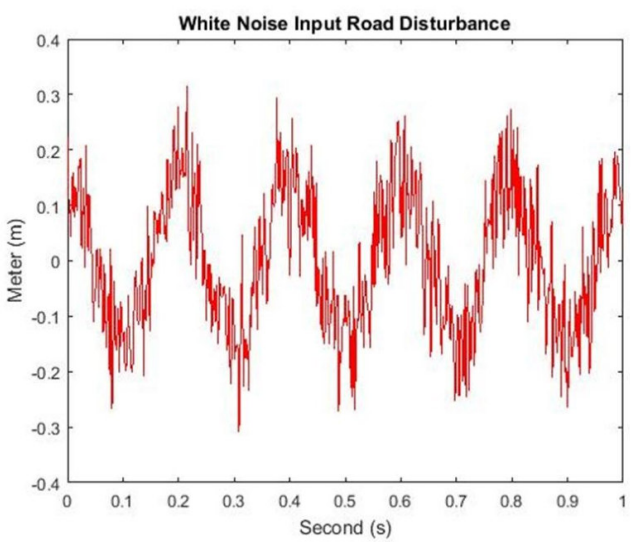

Figure 5: White noise road disturbance 


\section{The Proposed $\mu$-Synthesis Control Design \\ A. M-Synthesis Controller Design}

In the active suspension system, $\mu$-synthesis design covered the hydraulic actuator dynamics. In order to account for the distinction between the actuator model and the real actuator dynamics, we used a second order model of the actuator dynamics as well as an uncertainty model. The active suspension system with $\mu$-synthesis controller block diagram is shown in Figure 6.

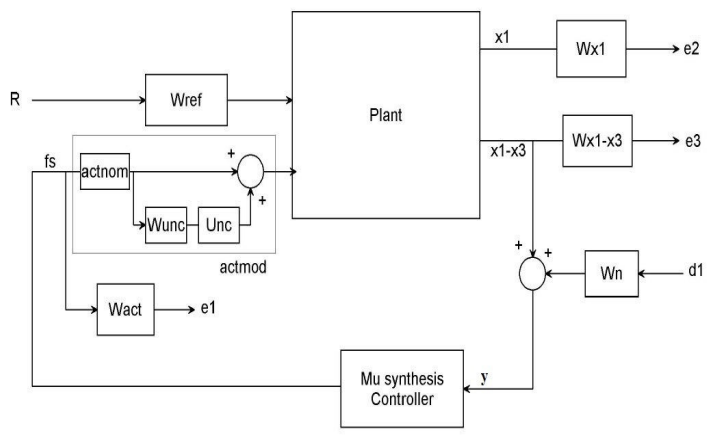

Figure 6: Active suspension system with $\mu$ - synthesis controller system interconnections block diagram The output or feedback signal y is

$$
y=\left(\left(x_{1}-x_{3}\right)+d_{1} \times W_{n}\right)
$$

The nominal model for the hydraulic actuator is

$$
\text { actnom }=\frac{s+2}{s^{2}+4 s+1}
$$

We describe the actuator model error as a hard and fast of viable models using a weighting function due to the fact the actuator model itself is uncertain. The model uncertainty is represented through weight Wunc which corresponds to the frequency variant of the model uncertainty and the uncertain LTI dynamics object Unc that is

$$
W_{u n c}=\frac{5 s+15}{67 s^{2}+16 s+1}
$$

Unc =Uncertain LTI dynamics"unc"with 1 outputs, 1 inputs, and gain less than 1

\section{B. LQR Controller}

In order to overcome a few problems that confronted via PID controller, the opposite sort of control strategies may be evolved such as Linear-Quadratic Regulator (LQR) most beneficial control. LQR is a control system that offers the satisfactory viable performance with recognize to some given measure of overall performance. The overall performance degree is a quadratic function composed of state vector and control input.

Linear Quadratic Regulator (LQR) is the most effective idea of pole placement technique. LQR set of rules defines the optimal pole location based on two cost function. To discover the optimal gains, one must outline the optimal performance index first off after which resolve algebraic Riccati equation. LQR does now not have any specific solution to outline the cost function to gain the most suitable gains and the cost function must be defined in iterative manner.

LQR is a control scheme that gives the high-quality viable overall performance with respect to a few given degree of performance. The LQR design hassle is to design a state feedback controller $\mathrm{K}$ such that the objective function $\mathrm{J}$ is minimized. In this technique a feedback gain matrix is designed which minimizes the objective function a good way to gain some compromise among the usage of control effort, the magnitude, and the speed of response on the way to assure a stable system. For a continuous-time linear system defined by means of

$$
\dot{x}=A x+B u
$$

With a cost functional defined as

$$
J=\int\left(x^{T} Q x+u^{T} R u\right) d t
$$

Where $\mathrm{Q}$ and $\mathrm{R}$ are the weight matrices, $\mathrm{Q}$ is required to be positive definite or positive semi-definite symmetry matrix. $\mathrm{R}$ is required to be positive definite symmetry matrix. One practical method is to $\mathrm{Q}$ and $\mathrm{R}$ to be diagonal matrix. The value of the factors in $\mathrm{Q}$ and $\mathrm{R}$ is associated with its contribution to the cost function $\mathrm{J}$. The comments control law that minimizes the value of the cost is:

$$
u=-K x
$$


$\mathrm{K}$ is given by

$$
K=R^{-1} B^{T} P
$$

And $\mathrm{P}$ can be located through solving the continuous time algebraic Riccati equation:

$$
A^{T} P+P A-P B R^{-1} B^{T} P+Q=0
$$

The value of weighted matrix $\mathrm{Q}$ (state penalty) and $\mathrm{R}$ (control penalty) relies upon on designer. Designer pick the ideal cost of $\mathrm{Q}$ and $\mathrm{R}$ to locate an appropriate advantage matrix $\mathrm{K}$ the use of MATLAB. The State variable feedback configuration is shown below in Figure 7.

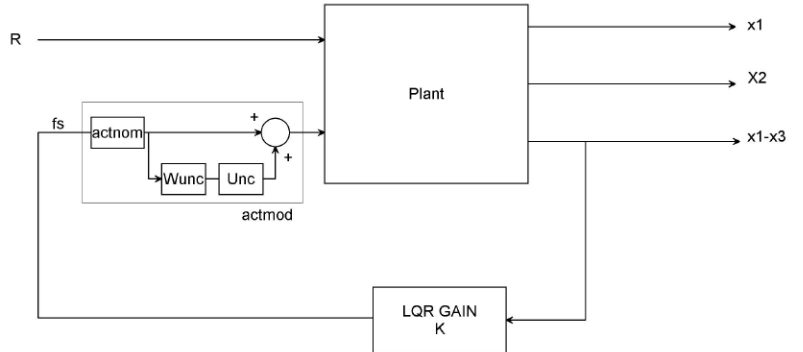

Figure 7: State variable feedback configuration

\section{By taking}

$$
Q=\left[\begin{array}{llll}
5 & 0 & 0 & 0 \\
0 & 5 & 0 & 0 \\
0 & 0 & 5 & 0 \\
0 & 0 & 0 & 5
\end{array}\right] \text { And } R=\left[\begin{array}{ll}
1 & 0 \\
0 & 1
\end{array}\right]
$$

The value of obtained feedback gain matrix $\mathrm{K}$ of $\mathrm{LQR}$ is given by

$$
K=\left[\begin{array}{llll}
-4.1189 & -0.1434 & 3.4141 & 0.2485 \\
-1.4657 & -0.0557 & 1.4983 & 0.0999
\end{array}\right]
$$

\section{RESULT AND DISCUSSION}

\section{A. Comparison of the active suspension system with $\mu$-synthesis and LQR controllers}

The simulation outcomes for bump input road profile for suspension deflection, body acceleration and body travel is shown in Figure 8, Figure 9 and Figure 10 respectively.

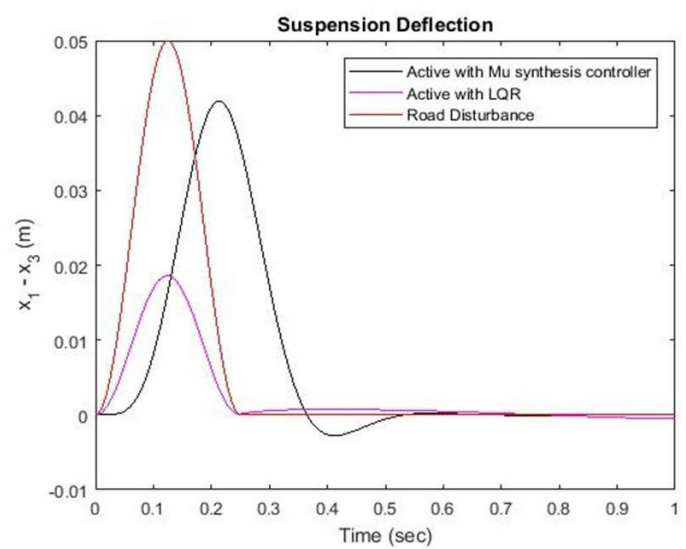

Figure 8: Suspension deflection for bump road disturbance 


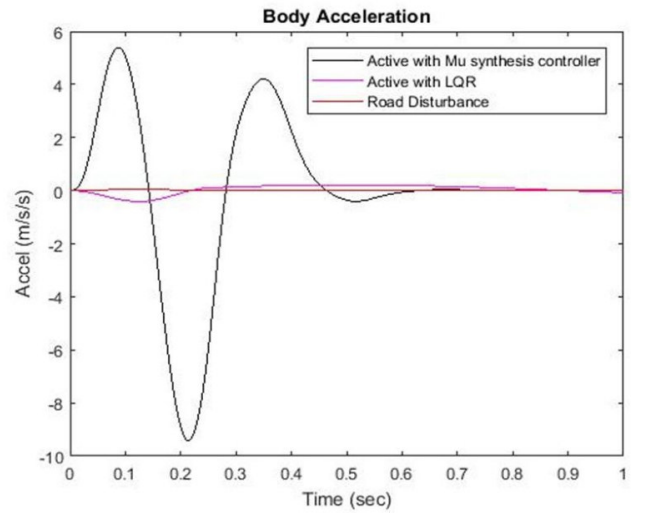

Figure 9: Body acceleration for bump road disturbance

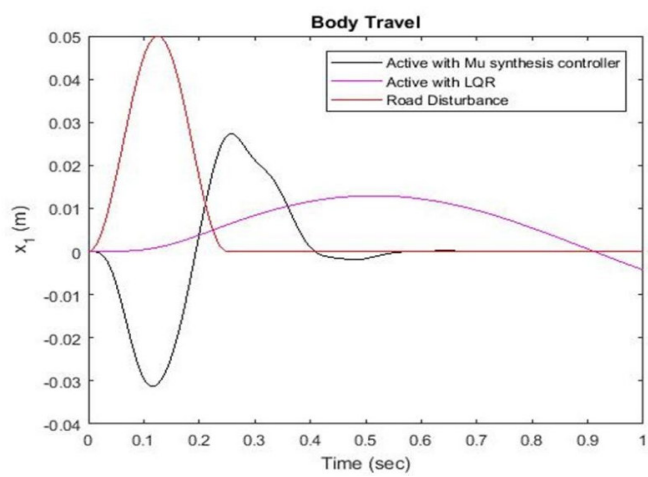

Figure 10: Body travel for Bump road disturbance

The simulation outcomes for random input road profile for suspension deflection, body acceleration and body travel is shown in Figure 11, Figure 12 and Figure 13 respectively.

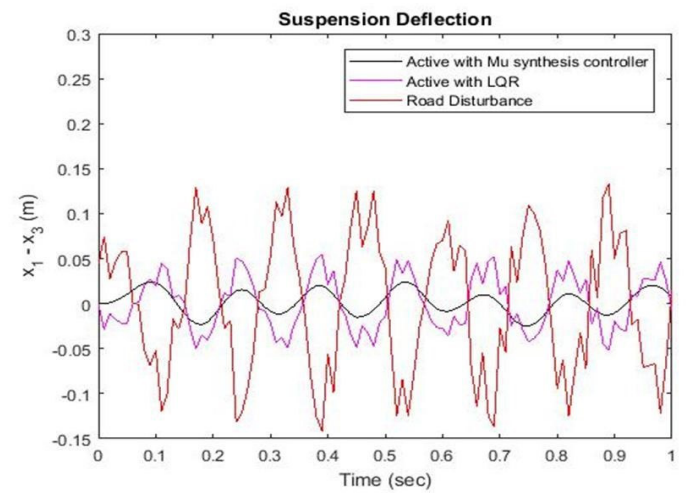

Figure 11: Suspension deflection for random road disturbance

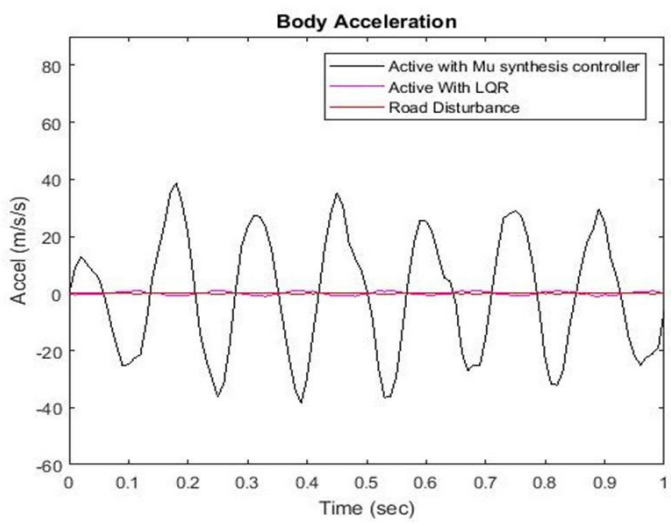

Figure 12: Body acceleration for random road disturbance 


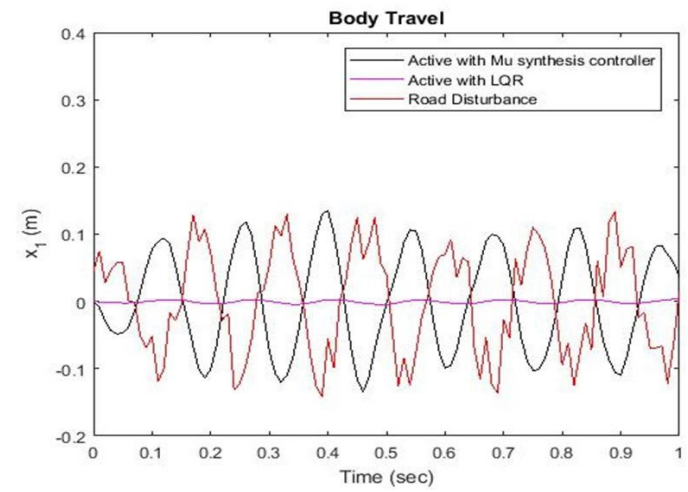

Figure 13: Body travel for random road disturbance

The simulation outcomes for sine pavement input road profile for suspension deflection, body acceleration and body travel is shown in Figure 14, Figure 15 and Figure 16 respectively.

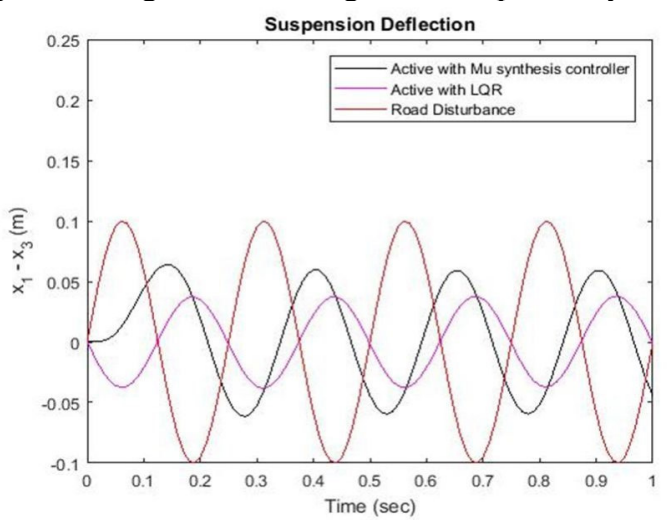

Figure 14: Suspension deflection for sine pavement road disturbance

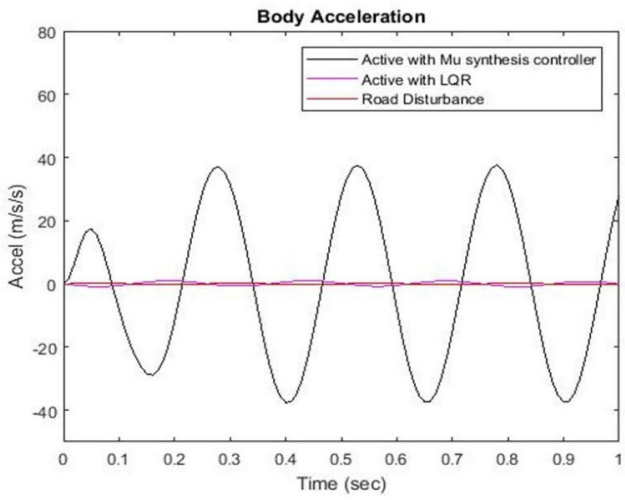

Figure 15: Body acceleration for sine pavement road disturbance 


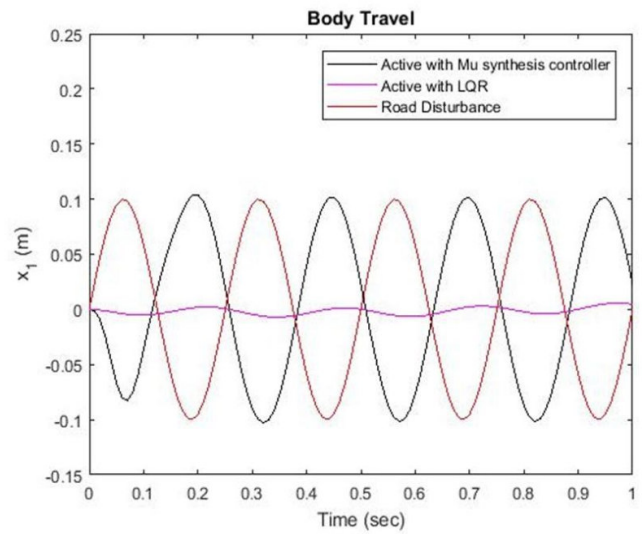

Figure 16: Body travel for sine pavement road disturbance

The simulation outcomes for white noise input road profile for suspension deflection, body acceleration and body travel is shown in Figure 17, Figure 18 and Figure 19 respectively.

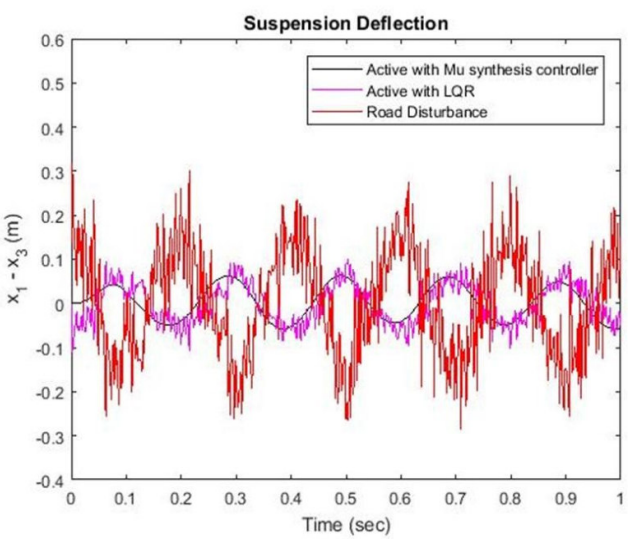

Figure 17: Suspension deflection for white noise road disturbance

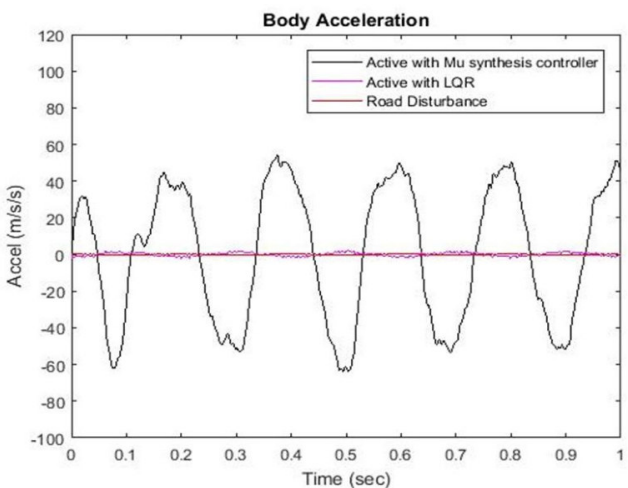

Figure 18: Body acceleration for white noise road disturbance 


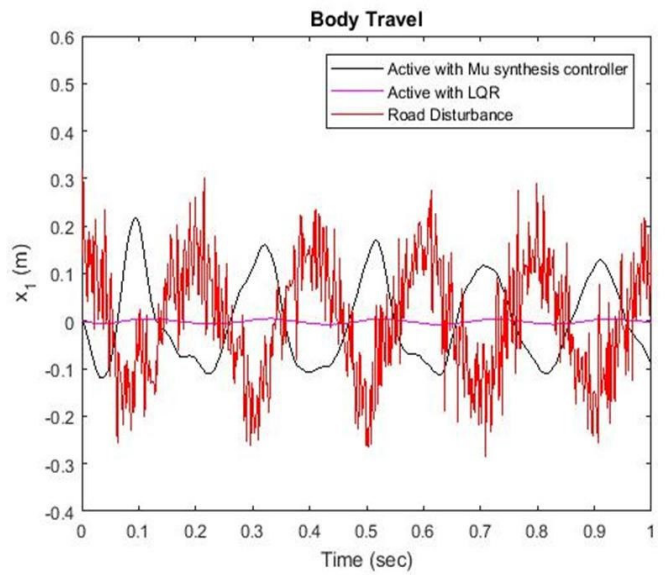

Figure 19: Body travel for white noise road disturbance

In the suspension deflection for the 4 road input profiles, Figure 8, Figure 14 and Figure 17 suggests that the active suspension system with $\mu$-synthesis controller has the excellent overall performance and Figure 11 suggests the active suspension system with LQR controller has the best performance.

In the body acceleration all of the simulation shows that the active suspension system with LQR controller has the best overall performance.

In the body travel all the four simulation indicates that the active suspension system with $\mu$-synthesis controller has the best performance. From all of the simulation results, we conclude that the active suspension system with $\mu$-synthesis controller has the best overall performance over the active suspension system with LQR controller.

\section{Conclusion}

In this paper, optimal control and robust control have been successfully designed ( $\mu$-synthesis and LQR controllers) using Matlab/Script program using time domain analysis using a control targets suspension deflection, body acceleration and body travel for a bump, random, sine pavement and white noise road profiles.

Finally, the simulation results prove the effectiveness of the active suspension system with $\mu$-synthesis controller for improving the passenger ride comfort and road handling criteria for the suspension system.

\section{ACKNOWLEDGMENT}

First and formost, I would like to express my deepest thanks and gratitude to Dr.Parashante and Mr.Tesfabirhan for their invaluable advices, encouragement, continuous guidance and caring support during my journal preparation.

Last but not least, I am always indebted to my brother, Taha Jibril, my sister, Nejat Jibril and my family members for their endless support and love throughout these years. They gave me additional motivation and determination during my journal preparation.

\section{REFERENCES}

[1]. Sairoel Amertet "Design of Optimal Linear Quadratic Regulator (LQR) Control for Full Car Active Suspension System Using Reduced Order "National Academic Digital Respiratory of Ethiopia, October 15, 2019.

[2]. Julian Asenov Genov et.al "A Linear Quadratic Regulator synthesis for a semi-active Vehicle Suspension Part-2 Multi-Objective Synthesis” AIP Conference Proceedings 2172, 110007, 2019.

[3]. Haijing Yan et.al "The Optimal Control of Semi-active Suspension based on Improved Particle Swarm Optimization” Mathimatical Models in Engineering, Vol. 4 Issue 3, p.157-163, 2018.

[4]. I.A Daniyan et.al "Design and Simulation of a Controller for an Active Suspension System of a Rail Car" Journal of Cogent Engineering, 2018.

[5]. Satyanarayana et.al "Parameters Optimisation of Vehicle Suspension System for Better Ride Comfort" International Journal of Vehicle Performance, Vol.4 No.2, 2018.

[6]. Jeng-Lang $\mathrm{Wu}$ "A Simultaneous Mixed LQR/H $\infty$ Control Approach to the Design of Reliable Active Suspension System” Asian Journal of Control, March, 2017.

[7]. Van Tan Vu "Using the LQR Control Method on the Active Suspension System of Automobiles" National Conference on Mechanics, 2017.

[8]. Huan XIE, Hong-yan WANG and Qiang RUI "Research on Optimal Control Method of Active Suspension Based on AMEsim Modeling” 2017 2nd International Conference on Mechanical Control and Automation 
(ICMCA 2017) ISBN: 978-1-60595-460-8, 2017.

[9]. Fumiaki Yamada and Kohei Suzuki "Robust Control of Active Suspension to Improve Ride Comfort with Structural Constraints" IEEE Advanced Motion Control, Auckland New Zealand, April 22-24, 2016.

[10]. Mohammed Jawad Aubad and Hatem Rahem Wasmi "A New Proposed Variable Stiffness of the Vehicle Suspension System Passive Case: I” Innovative Systems Design and Engineering www.iiste.org ISSN 22221727 (Paper) ISSN 2222-2871 (Online) Vol.7, No.5, 2016.

[11].K. Dhananjay Rao and K. Pavani "Modelling and Vibration Control of Suspension System for Automobiles using LQR and PID Controllers" IJLTEMAS ISSN 2278 - 2540, Volume IV, Issue VIII, August 2015.

[12].B. Sepehri and A.Hemati "Active Suspension vibration control using Linear H-Infinity and optimal control" International Journal of Automotive Engineering Vol. 4, Number 3, Sept 2014.

[13].Md. Kaleemullah and Waleed F. Faris "Active Suspension Control of Vehicle with Uncertainties using Robust Controllers” Int. J. Vehicle Systems Modelling and Testing, Vol. 9, Nos. 3/4, 2014. 